\title{
DETERMINANTES PARA A FORMAÇÃO DA CULTURA EMPREENDEDORA: A EXPERIÊNCIA DO PROJETO DESAFIO SEBRAE.
}

\author{
DETERMINANTS FOR THE FORMATION OF THE ENTREPRENEURIAL CULTURE: THE \\ EXPERIENCE PROJECT DESAFIO SEBRAE.
}

\section{Maurício Mendes Boavista de Castro mauricioboavista@ufpi.edu.br \\ Universidade Federal do Piauí - Teresina - PI - Brasil}

\section{Sérgio Aquino de Souza}

srgdesouz@gmail.com

Universidade Federal do Ceará - Fortaleza - CE - Brasil

\section{João Carlos Hipolito B. Nascimento}

jchbn1@gmail.com

Universidade Federal do Piauí - Teresina - PI - Brasil

\section{Leonardo Victor de Sá Pinheiro}

leonardopinheiro@hotmail.com

Universidade Federal do Piauí - Teresina - PI - Brasil

\section{Juliana Reis Bernardes}

jureis3d@hotmail.com

Universidade Federal do Piauí - Teresina - PI - Brasil

\section{Resumo}

O presente estudo, de caráter descritivo, foi operacionalizado por meio de levantamento de dados com os alunos piauienses que participaram do jogo de empresas desafio SEBRAE. Nesse aspecto, o objetivo do presente estudo foi verificar se o jogo de empresas Desafio SEBRAE apresenta influência significativa para que o estudante universitário piauiense obtenha uma visão empreendedora. Considerando que política de aplicação de jogos e simulações nas escolas e instituições formadoras de futuros profissionais de mercado ajuda significativamente à sua formação empreendedora, pôde-se notar, dentre os achados da pesquisa, que o jogo virtual Desafio SEBRAE cumpre seu papel, seja completando a lacuna não preenchida pelo sistema de Ensino Superior padrão, seja motivando a cultura empreendedora dos alunos através da incursão prática que as simulações de mercado oferecem.

Palavras-chave: Jogos de Empresas; Empreendedorismo; Ensino Superior.

\section{Abstract}

The current study of character descriptive was operationalized through of survey data piauienses students that will play business Desafio SEBRAE. Thus, the purpose of this study was check if the game business Desafio SEBRAE presents significant influence for the student piauiense get a vision entrepreneurial. Whereas policy implementation of games and simulations in schools and institutions formators futures market professionals help meaningful 


\section{Maurício Mendes Boavista de Castro, Sérgio Aquino de Souza, João Carlos Hipolito B. Nascimento, Leonardo Victor de Sá Pinheiro, Juliana Reis Bernardes}

in your entrepreneurial training, up might consider, among the findings of the research, the game virtual Desafio SEBRAE meets your paper is completing a lacuna not completed by the higher education system standard, whether motivating students of entrepreneurial culture through incursion practice that the simulation of market offer.

Keywords: Games of Company. Entrepreneurship. Higher Education.

\section{Introdução}

Nas últimas décadas, sobretudo em decorrência do fenômeno da globalização, o problema do desemprego vem se acentuando de forma preocupante, impondo condições obrigatórias de mudanças, principalmente, no que diz respeito à absorção da população economicamente ativa (KRUGMAN; WELLS, 2012) e, cada vez mais, qualificada pelas ações que possibilitam um melhor e mais fácil acesso ao Ensino Superior e Técnico.

Nesse contexto, os movimentos empreendedoristas se alastram pelos continentes, evidenciando os caminhos para os negócios próprios e, consequentemente, incrementando a absorção de profissionais, diminuindo o encargo governamental e propiciando gerações de receitas adicionais para investimentos públicos. Nota-se em todo o mundo a majoração da relevância do segmento empresarial para o crescimento e desenvolvimento das economias, uma vez que, é responsável por grande percentual de absorção de mão de obra e renda gerada.

Particularizando para o Estado do Piauí, o quadro descrito é ainda mais relevante, por se tratar do Estado com menor desenvolvimento do País e com uma das menores rendas per capita (IBGE, 2013). No caso do Piauí, portanto, é necessário, cada vez mais, que se implementem ações que estimulem a criação de novas empresas para suportar a grande demanda por emprego, contribuindo assim, para a redução dos altos índices de desemprego e de miséria do Estado.

É notada a existência de uma importante parcela das empresas, principalmente micros e pequenos empreendimentos, que não dispõem de um planejamento que possibilite aumentar o seu poder de competitividade e, assim, fazer frente ao atual mercado globalizado, sofrendo como consequência dessa carência, com um alto índice de mortalidade. Isso se deve, em parte, ao fato dos dirigentes empreendedores não terem uma capacitação e uma visão apropriada que os credenciem a gerir negócios autossustentáveis e capazes de sobreviver em um mundo tão competitivo quanto o contemporâneo (SEBRAE, 2013).

A despeito da realidade descrita, não foram encontrados na literatura estudos focados em analisar a influência de programas de fomento ao empreendedorismo. Nesse ensejo, foi proposto analisar a capacidade empreendedora futura a partir de ações que tenham a finalidade de formar os futuros empreendedores e, particularmente, a partir dos alunos que participaram do projeto jogos de empresas DESAFIO SEBRAE realizado pelo Serviço de Apoio às Micro e Pequenas Empresas - SEBRAE no Estado do Piauí.

No Brasil, o segmento das empresas de micro e pequeno porte é de fundamental importância para a economia, afinal, é responsável por $60 \%$ do emprego da mão de obra economicamente ativa, $42 \%$ dos salários pagos, e representa $20 \%$ do PIB - Produto Interno Bruto. Atualmente, compreende aproximadamente $99 \%$ dos 6 milhões de estabelecimentos no país (PORTAL BRASIL, 2012).

Assim, com o objetivo de operacionalizar o presente estudo, buscou-se investigar o seguinte problema de pesquisa: qual a influência do jogo de empresas DESAFIO SEBRAE para a formação de uma visão empreendedora do estudante universitário piauiense? Nesta perspectiva, buscou- 


\section{DETERMINANTES PARA A FORMAÇÃO DA CULTURA EMPREENDEDORA: A EXPERIÊNCIA DO PROJETO DESAFIO SEBRAE.}

se conhecer a real situação desses estudantes com relação à problemática levantada.

Justifica-se a realização da presente pesquisa, uma vez que, apresenta potencial de contribuir para o aperfeiçoamento de ações voltadas para a cultura empreendedora, especialmente no tocante ao estímulo à abertura de novas empresas, com condições de competir no mercado globalizado. Ao mesmo tempo, o estudo estará contribuindo para a criação de condições de continuidade dos negócios existentes com eficiência competitiva no atual cenário de competição acirrada, além de oferecer às instituições de ensino superior subsídios sobre os resultados do aprendizado dos alunos sobre o assunto.

O estudo está organizado, além desta introdução, em quatro seções. Inicialmente é apresentada a fundamentação teórica. Na segunda, são dispostos os aspectos metodológicos utilizados na investigação. Na terceira seção é apresentada a discussão dos dados e, por último, são evidenciadas as considerações finais com as limitações do estudo e indicações de oportunidades para o desenvolvimento de futuras pesquisas.

\section{Referencial teórico}

\section{O empreendedorismo como abordagem econômica}

O empreendedorismo, atualmente, é um tema obrigatório nos planos governamentais, nas escolas públicas e privadas e, principalmente, nas instituições de ensino técnico e superior, como forma de propiciar condições mais favoráveis para a geração de oportunidades de trabalho, ocupação e renda.

Segundo Dolabela (1999) o termo "empreendedorismo" é uma livre tradução da palavra entrepreneurship, utilizado para designar os estudos relativos ao empreendedor, seu perfil, suas origens, seu sistema de atividades e o seu universo de atuação. 0 termo designa uma área de grande abrangência, além da criação de empresas, englobando a geração do auto emprego, empreendedorismo comunitário e funcional. Para o autor, o empreendedor é alguém que define por si mesmo o que vai fazer e em que contexto será feito. Ao definir o que vai fazer, ele leva em conta seus sonhos, desejos, preferências, o estilo de vida que quer ter. Desta forma, consegue dedicar-se intensamente, já que seu trabalho se confunde com o prazer.

Entende-se que ser empreendedor é criar algo novo e duradouro para si mesmo, mudando ou transformando valores. Não é um simples traço da personalidade de alguém, mas um comportamento baseado em conceitos bem definidos e não apenas em intuição. Percebe-se, portanto, que ser empreendedor não é apenas abrir ou adquirir um negócio, é preciso prospectar oportunidades, estabelecendo valores e melhorando concepções e, assim, poder assumir riscos inerentes a quaisquer investimentos. Vale ressaltar que, em todos os conceitos que se pode ter de empreendedorismo, palavras como inovação, oportunidades, mudança e iniciativa estão sempre presentes.

Empreendedorismo é o processo de descobrir ou desenvolver uma oportunidade para então, gerar valores através da inovação e, agarrando tal oportunidade sem levar em conta um ou outro recurso (humano e capital), como também, sem levar em consideração a posição do empreendedor dentro da nova ou já existente empresa (SEXTON; KASARDA, 1992).

0 fenômeno do empreendedorismo, ainda sem nome, surgiu antes mesmo da descoberta da língua escrita. Mesmo não incorporado pelos gramáticos, o termo empreendedorismo, sempre existiu, haja vista o longo e contínuo percurso de domínio natural por parte dos seres humanos que inventaram embarcações, construíram casas, conceberam a arte de tecer e descobriram as 


\section{Maurício Mendes Boavista de Castro, Sérgio Aquino de Souza, João Carlos Hipolito B. Nascimento, Leonardo Victor de Sá Pinheiro, Juliana Reis Bernardes}

possibilidades do metal (MARCOVITCH, 2005).

Pela própria necessidade atual existente, o empreendedorismo passou a ser importante área de investigação, principalmente nas Ciências Sociais Aplicadas, sobressaindo-se nesse caso a Administração e a Economia, sendo, portanto, um conceito novo e ainda em formação. Para Dolabela (1999), o empreendedorismo, enquanto campo de pesquisa acadêmica, é ainda considerado um tema bastante novo, podendo definir a sua idade dentro das últimas duas décadas.

Na economia, Schumpeter (1997) foi um dos pioneiros em abordar o assunto com mais ênfase, vinculando-o à ideia de inovação. Para ele, a essência do empreendedorismo está na percepção e no aproveitamento das novas oportunidades no âmbito dos negócios tradicionais, constantemente formulando novos produtos. Assim, como também novos métodos de produção e mercados, sobrepondo-os aos antigos métodos que, segundo o economista, eram considerados menos eficientes e mais caros.

Schumpeter (1961) afirma que o empreendedor exerce o papel de motor do crescimento econômico, desafiando as empresas estabelecidas no mercado, ao introduzir inovações que fomentam a obsolescência dos produtos e tecnologias existentes. Schumpeter (1984) complementa a ideia ao afirmar que, através dos elevados investimentos em Pesquisa e Desenvolvimento (P\&D), somente as empresas de grande porte e poder de mercado detém capacidade de promover inovações com potencialidade de fomentar a obsolescência dos produtos.

Audretsch et al. (2006) contribuíram na discussão acerca da influência do empreendedorismo e o crescimento econômico ao desenvolverem a Teoria do Empreendedorismo decorrente do Transbordamento do Conhecimento (Knowledge Spillover Theory of Entrepreneurship), que propõem que as novas ideias desenvolvidas em laboratórios de pesquisa de grandes empresas ou universidades, mas não aproveitadas comercialmente por estas, geram oportunidades empreendedoras.

Audretsch et al. (2006) desenvolveram a hipótese de que níveis mais altos de crescimento econômico são resultantes de atividade empreendedora mais recorrente, dado que 0 empreendedorismo facilita o transbordamento e a comercialização do conhecimento.

Entretanto, a relação entre empreendedorismo e crescimento econômico sofre influência do estágio de desenvolvimento do país (AGHION; HOWITT, 2005), tendo em vista que o incremento de novos empreendimentos tem efeito positivo mais importante no crescimento econômico em países que estão mais próximos da fronteira tecnológica, enquanto apresenta efeito estatisticamente inferior em países que se posicionem abaixo da fronteira (BARROS; PEREIRA, 2008).

O papel do empreendedor, enquanto responsável pela geração de riquezas, passa a ser analisado pela escola econômica, entretanto, por priorizar modelos quantitativos, os economistas, ainda hoje, não conseguiram desenvolver uma ciência atitudinal voltada principalmente para o comportamento dos empreendedores.

Pelas grandes e muitas contribuições, estudos e pesquisas sobre o empreendedorismo, surgem variadas correntes que dão enfoque prioritariamente para os aspectos econômicos. A partir de então, os economistas passam a enxergar os empreendedores como pessoas inovadoras e agentes catalisadores do desenvolvimento. 


\section{DETERMINANTES PARA A FORMAÇÃO DA CULTURA EMPREENDEDORA: A EXPERIÊNCIA DO PROJETO DESAFIO SEBRAE.}

\section{A utilização de jogos como ferramenta educacional}

A utilização dos jogos empresariais como ferramenta de ensino e aprendizagem iniciou-se em 1956 nos Estados Unidos da América (EUA) com o jogo Top Management Decision Game, uma adaptação dos jogos da área militar para o ambiente empresarial, que tinha como objetivo treinar executivos da área financeira (SAUAIA, 1997).

Também nos EUA, em 1974, foi criada a Association for Business Simulation and Experiential Learning, composta por docentes de Administração e disciplinas afins com o objetivo de desenvolver e incentivar a utilização de jogos empresariais como ferramenta de ensino (ROSAS; AZUAYA, 2006).

No Brasil, a utilização de jogos empresariais iniciou-se na década de 70 na Faculdade Getúlio Vargas EAESP e na Faculdade de Economia, Administração e Contabilidade da Universidade de São Paulo (GOLDSCHMIDT, 1977; TANABE, 1973; WARSCHAUER, 1977). Na década de 80 podese destacar o Programa de Pós-graduação em Engenharia de Produção da Universidade Federal de Santa Catarina (UFSC) que iniciou um centro de desenvolvimento de jogos para aplicação em educação e pesquisa na área de Engenharia de Produção e áreas relacionadas de gestão (LOPES, 2001).

Nesse aspecto, a utilização dos microcomputadores foi um fator relevante à proliferação dos jogos ao possibilitar o processamento de dados com maior rapidez, o que possibilitou o desenvolvimento de jogos mais complexos, dinâmicos e com um alto nível de precisão (FREITAS; SANTOS, 2003).

Mais recentemente, o advento da internet possibilitou a interatividade e, principalmente, incrementou o aprendizado através da construção coletiva e em tempo real (jogos on line) culminando com o estabelecimento de comunidades virtuais. Segundo Stahl e Lopes (2004), os jogos empresariais possibilitou aos alunos maior autonomia na obtenção de conhecimento, tornando-os autodidatas.

Segundo Rosas e Azuaya (2006), os jogos empresariais simplificam uma realidade empresarial complexa, delimitando as variáveis com as quais desejam-se trabalhar, restringindo-se $o$ impacto de outras variáveis no modelo. Sauaia (1989, p. 66) contribui afirmando que "como um exercício de tomada de decisões, os jogos têm por objetivo reproduzir parcialmente e de forma simplificada uma situação que poderia ser real...".

Pretto (2007) define jogos empresariais como uma técnica de ensino capaz de simular situações projetadas com o intuito de representar as condições reais encontradas no mundo dos negócios. Já Sauaia e Zerrenner (2009) caracterizam jogos empresariais como um exercício sequencial de tomada de decisões no qual os discentes se encarregam da tarefa de administrar as empresas simuladas.

Stahl e Lopes (2004) contribuem apresentando os benefícios advindos da utilização de jogos empresariais como ferramenta de ensino na graduação em Administração, a saber: evitar perdas econômicas, ao possibilitar que os graduandos cometam erros sem expor o capital dos investidores; o exercício da tomada de decisão estratégica no momento em que reduz o tempo inerente a decisões desse tipo; e incrementar o realismo ao aproximar o aluno da realidade empírica onde atuará profissionalmente.

Por fim, acerca dos objetivos, Pretto (2007) cita os três principais, a saber: aumentar os conhecimentos, desenvolver habilidades e fixar atitudes. 


\section{Maurício Mendes Boavista de Castro, Sérgio Aquino de Souza, João Carlos Hipolito B.}

Nascimento, Leonardo Victor de Sá Pinheiro, Juliana Reis Bernardes

\section{Breve revisão da literatura sobre jogos educacionais como ferramenta educacional}

Santos (2003) estudou a aplicação dos jogos empresariais em Contabilidade. Para tal, através do desenvolvimento de um software projetado para o ensino e aprendizagem em Contabilidade, foi notado que esta estratégia de ensino e aprendizagem deve ser aplicada em um contexto de aprendizagem de adultos, sob o enfoque da educação centrada no aluno e através de uma perspectiva de trabalhos em equipe.

Stahl e Lopes (2004), suportados em experiências de estudantes participantes de jogos empresariais, e sob o prisma da pedagogia, realizaram uma pesquisa bibliográfica visando sistematizar e compreender mais claramente acerca da avaliação da aprendizagem dos participantes nos jogos de empresas.

Os autores concluíram que os jogos e simulações empresariais têm potencial de possibilitar a realização de reflexões acerca das eventuais falhas no processo de formação dos discentes. Adicionalmente Stahl e Lopes (2004) notaram que jogos empresariais podem e devem ser encarados como um processo de avaliação curricular, diagnosticando falhas/fragilidades em determinadas áreas do curso.

Rosas e Sauaia (2006) buscaram captar a percepção de professores doutores cadastrados na base Lattes do CNPq acerca das perspectivas acadêmicas à adoção dos jogos empresariais na formação de administradores, incluindo fatores incentivadores e dificultadores. Entre outros resultados, os autores notaram que, na percepção dos docentes participantes da pesquisa, o principal fator incentivador é a demanda dos alunos, enquanto a existência de facilitadores capacitados para fornecer o treinamento poderá tornar-se a maior restrição.

Sauaia e Zerrenner (2009), por meio de análise empírica de comportamentos em jogos de empresas e inspirados na discussão das teorias clássicas da tomada de decisão, buscaram alcançar evidências empíricas de como os indivíduos processam a informação recebida para tomada de decisões.

Os autores notaram que, alinhado à literatura teórica prévia de economia e finanças comportamentais, as escolhas mostraram-se racionais, entretanto, de forma limitada em decorrência de alguns fatores cognitivos: simplificação; falta de critérios; restrição de tempo e de custo; percepção; capacidade de retenção da memória.

Pires, Oi e Teixeira (2012) investigaram a relevância dos jogos de empresas como método de desenvolvimento das características empreendedoras segundo a percepção dos discentes do curso de Administração de Empresas da Faculdade de São Paulo do grupo UN0049ESP.

Conduzindo uma pesquisa descritiva qualitativa com estudos de casos realizados com 252 alunos, os autores concluíram que a aplicação dos jogos empresariais no curso de Administração de Empresas apresenta grande contribuição para o desenvolvimento das características empreendedoras.

Entretanto, não foram estudos focados em analisar a influência de programas de fomento ao empreendedorismo, especialmente focados no DESAFIO SEBRAE, e na capacidade empreendedora futura dos alunos, lacuna essa explorada no presente estudo.

\section{O jogo Desafio SEBRAE como instrumento formador da capacidade empreendedora das pessoas}

Desenvolvido pelo Serviço Brasileiro de Apoio às Micro e Pequenas Empresas - SEBRAE e a 


\section{DETERMINANTES PARA A FORMAÇÃO DA CULTURA EMPREENDEDORA: A EXPERIÊNCIA DO PROJETO DESAFIO SEBRAE.}

Coordenação dos Programas de Pós-Graduação em Engenharia da Universidade Federal do Rio de Janeiro - COPPE/UFRJ, o jogo DESAFIO SEBRAE foi criado para servir como instrumento de disseminação e formação da cultura empreendedora na comunidade do ensino formal, especificamente, àquela pertencente às instituições de Ensino Superior no Brasil, tendo, a partir de 2005, pelos resultados positivos alcançados, ampliado a sua atuação em outros sete países da América do Sul.

Há muito tempo, a prática da utilização de jogos e simulações como forma de capacitar melhor gestores e profissionais empreendedores vem crescendo e sendo mais aceita, uma vez que, além de ser exercitados o conhecimento formal, o praticante passa a ter, também, experiências vivenciais em conceitos como sinergia, tomada de decisões, criatividade, projeções, elaboração e leituras de estratégias, além de trabalhar modelos de gestão.

Para que o aprendizado não se prenda a um único tema, o jogo vivencia diferentes tipos de empresas atuando em segmentos produtivos variados. Desde quando foi criado, em 2000, o jogo já foi desenvolvido em 13 (treze) diferentes arranjos produtivos, desde indústria de artigos de Mármore no ano 2000 a Indústria de calçados no ano de 2008, por exemplo.

Segundo Gramigna (2000, p. 34), para que o aprendizado dos jogos e simulações seja alcançado, estes devem passar por, pelo menos, cinco fases distintas onde, juntas, formam um ciclo de aprendizado fundamentado na vivência oportunizada durante o período trabalhado. São elas:

1. Fase: vivência - Caracterizada pelo jogo propriamente dito, onde os jogadores/alunos participam ativamente da competição e onde acontecem várias atividades relacionadas com a construção de cenários mercadológicos; reprodução de modelos empresariais; discussão e montagens de estratégias; elaboração e análise de planilhas envolvendo custos, receitas, balanços e outros indicadores empresariais; processos de negociação e de tomadas de decisão; e, trabalhos envolvendo toda a equipe a partir da criatividade individual e coletiva em busca de soluções para os desafios que são encontrados;

2a Fase: relato - Fase em que toda a equipe passa a compartilhar sentimentos, reações e emoções, tudo isso influenciado pelo envolvimento que passam a ter na busca incansável de resolver os problemas, tomar as melhores decisões, ultrapassar desafios. Nesta fase, os participantes passam a ser afetados emocionalmente;

3 ${ }^{\text {a }}$ Fase: processsamento - Momento de análise e reflexão sobre todos os passos que já foram dados durante as etapas já ultrapassadas. Nesta fase, os participantes tem a chance de analisar as decisões tomadas e as suas consequências diante dos resultados alcançados, podendo ser discutidos os desempenhos conseguidos e o nível de interação entre eles;

4 ${ }^{\mathbf{a}}$ Fase: generalização - Fase em que a equipe tem a condição de fazer comparações e analogias do ocorrido durante o jogo e a realidade empresarial. Neste momento, os participantes voltam à realidade.

5 Fase: aplicação - última fase do jogo, esta propicia aos participantes a oportunidade de fazer as mudanças necessárias na sua conduta e conhecimento para que estas venham a servir como base para situações futuras que venham a ocorrer.

Os jogos de empresas têm se mostrado muito eficazes como ferramenta de ensinoaprendizagem e desenvolvimento gerencial, sendo uma das mais eficazes ferramentas à promoção de políticas públicas voltadas para a educação empreendedora (GERBER, 2000). Gerber (2000, p. 58) afirma ainda, que várias são as vantagens da aplicação desses jogos na 


\section{Maurício Mendes Boavista de Castro, Sérgio Aquino de Souza, João Carlos Hipolito B. Nascimento, Leonardo Victor de Sá Pinheiro, Juliana Reis Bernardes}

comunidade estudantil, entre elas, cita:

a) Treinamento do processo de tomada de decisão; b) Aplicação na prática de teorias gerenciais como marketing, produção, contabilidade, recursos financeiros e humanos, entre outras; c) Desenvolvimento de habilidades de trabalho em grupo; d) Oportunidade de experimentar, sem correr riscos de causar danos reais; e) Treinamento da interpretação e cenários, relatórios e gráficos empresariais; f) Aumento da capacidade de resolução de problemas; g) Capacidade de acelerar o tempo, possibilitando em apenas algumas jogadas simular um período de meses ou mesmo de anos; h) Alto envolvimento dos alunos ocasionado pelo ambiente competitivo formado pelas equipes que administram as empresas do jogo, já que a empresa que obtiver melhor desempenho se consagra campeã; i) Feedback rápido e continuo proporcionado as participantes; j) Integração dos conhecimentos das diferentes áreas da administração industrial; l) Elevado grau de realismo; m) Menor formalismo em relação a outros métodos de ensino. Os participantes discutem, preparam materiais expositivos e fazem pesquisas tal como aconteceria em seus ambientes de trabalho; n) Oportunidade de participação ativa dos membros mais introvertidos das equipes, oferecendo um ambiente que estimula mais autoconfiança; p) Variação das condições da atividade de acordo com as necessidades do grupo ou equipe; e, q) Por apresentarem características diferentes das encontradas em métodos de treinamento convencionais, os jogos costumem ser eventos memoráveis.

Vale ressaltar que, com o avanço das ferramentas metodológicas, principalmente ocasionadas pelas novas tecnologias empregadas, os jogos e simulações passaram a ser, cada vez mais, um retrato das condições mercadológicas e ambientais vividas pelas organizações.

\section{Metodologia da pesquisa}

\section{Caracterização do estudo}

O trabalho pode ser classificado como descritivo e procurou avaliar a ação relativa a jogos de empresas e simulações, o caso do DESAFIO SEBRAE, e as variáveis que contribuem para a formação da capacidade empreendedora dos estudantes universitários piauienses. A pesquisa descritiva foi realizada a partir do levantamento de dados primários e secundários, com a utilização de questionário com perguntas abertas e fechadas de forma estruturada.

\section{Universo e amostra}

O estudo foi realizado tendo como base de dados os alunos piauienses que participaram do Jogo de Empresas DESAFIO SEBRAE, na versão 2008, adotando-se uma seleção daqueles pertencentes às equipes participantes na etapa estadual do referido jogo, utilizando-se, portanto, uma seleção do tipo não probabilística intencional ou conveniência.

Conforme Lakatos e Marconi (1990), nesse tipo de seleção os elementos da amostra são obtidos de acordo com a conveniência do pesquisador e as características estabelecidas. Sendo assim, a amostra do trabalho será composta de 2 (dois) grupos de alunos. No primeiro grupo estarão àqueles alunos participantes do jogo que não conseguiram, pelas suas performances, passar da primeira rodada de tarefas/decisões e, no segundo grupo, estarão aqueles alunos que ficaram até a última rodada de tarefas/decisões.

Conforme Stevenson (1997), o tamanho de amostra foi obtido em função do tamanho da população, do nível de confiança desejado e da margem de erro aceitável. Sendo assim, para esse 


\section{DETERMINANTES PARA A FORMAÇÃO DA CULTURA EMPREENDEDORA: A EXPERIÊNCIA DO PROJETO DESAFIO SEBRAE.}

trabalho, a amostra foi calculada em função quantidades de alunos participantes na primeira e na última etapa do jogo, do nível de confiança desejado e da margem de erro aceitável.

Portanto, para um intervalo de confiança de 95\%, o tamanho da população foi de 510 alunos, onde 260 não conseguiram atingir a segunda etapa do jogo e 250 chegaram à última etapa, a amostra foi composta por 80 alunos. Ressalte-se que, para a aplicação dos questionários, utilizou-se uma amostra de 40 alunos que participaram do jogo, mas não conseguiram chegar à segunda fase e 40 alunos que chegaram à última etapa do DESAFIO SEBRAE.

\section{Técnicas de coleta de dados}

Como já foi especificado anteriormente, para a elaboração da pesquisa, foram utilizadas fontes primárias e secundárias, bem como aplicação de questionários organizados e padronizados com questões abertas e fechadas em consonância com o tema defendido. Os dados primários foram levantados com a utilização de questionário, elaborado na metodologia de Prado e Marchetti (1996), estruturado e constituído de perguntas fechadas ou dicotômicas, abertas e pessoais que, segundo Lakatos e Marconi (1991, p. 205), "permite obter-se respostas mais objetivas dos consumidores integrantes da amostra". A inclusão de perguntas abertas atende à especificidade dos conceitos intersubjetivos e motivacionais, importantes na análise.

Para validar a precisão e a validade do instrumento de obtenção dos dados, foi escolhida uma amostra de 50 alunos e aplicada uma pesquisa-teste. Após a detecção de algumas falhas, foram revisados e devidamente adequados para, somente então, serem aplicados em uma nova amostra de outros 50 entrevistados. Após essa segunda aplicação, a pesquisa definitiva foi realizada junto aos estudantes selecionados.

\section{Técnicas para análise dos dados}

Para a análise dos dados utilizou-se o software Econometric Views - E-views 5.0, pacote estatístico que possibilita, entre outros procedimentos, a manipulação de dados de séries temporais. Com base nas perguntas do questionário aplicado, dezenove variáveis binárias foram formuladas para a utilização na pesquisa empírica; a descrição destas variáveis pode ser vista na Tabela 1:

\begin{tabular}{|c|c|c|c|}
\hline Cod. & Variável & 1 & $\boldsymbol{O}$ \\
\hline $\bar{Y}$ & Participante & Se Sucesso & Se Fracasso \\
\hline$X 1$ & Sexo & Se Masculino & Se Feminino \\
\hline$X 2$ & Idade & $\begin{array}{l}\text { Se menor ou } \\
\text { igual a } 25 \text { anos }\end{array}$ & $\begin{array}{l}\text { Se tem mais de } \\
25 \text { anos }\end{array}$ \\
\hline$X 3$ & Como vive & $\begin{array}{l}\text { Se vive com os } \\
\text { pais }\end{array}$ & Caso contrário \\
\hline$X 4$ & Faixa de renda familiar & $\begin{array}{l}\text { Se menor ou } \\
\text { igual a } 5 \text { S.M. }\end{array}$ & $\begin{array}{l}\text { Se mais de } 5 \\
\text { S.M. }\end{array}$ \\
\hline$X 5$ & Onde estudou o ensino fundamental & Se Privado & Se Publico \\
\hline$X 6$ & Onde estudou o ensino médio & Se Privado & Se Publico \\
\hline
\end{tabular}




\begin{tabular}{|c|c|c|c|}
\hline$X 7$ & Profissão do Pai & $\begin{array}{l}\text { Iniciativa } \\
\text { Privada }\end{array}$ & $\begin{array}{l}\text { Se Funcionário } \\
\text { Público }\end{array}$ \\
\hline$X 8$ & Profissão da Mãe & $\begin{array}{l}\text { Iniciativa } \\
\text { Privada }\end{array}$ & $\begin{array}{l}\text { Se Funcionária } \\
\text { Pública }\end{array}$ \\
\hline$X 9$ & Área do curso que está regularmente matriculado & Se ADM ou afins & Caso contrário \\
\hline$X 10$ & Tipo da Instituição em que estuda & Se Publico & Se Privado \\
\hline$X 11$ & Tempo de Curso & Se até a metade & $\begin{array}{l}\text { Se mais que a } \\
\text { metade }\end{array}$ \\
\hline$X 12$ & Já participante do jogo DESAFIO SEBRAE & Se sim & Se não \\
\hline$X 13$ & Quanto à intenção de ter o próprio negócio & Se sim & Se não \\
\hline$X 14$ & Exercício de uma atividade profissional. & Se sim & Se não \\
\hline$X 15$ & $\begin{array}{l}\text { A atividade que está exercendo é na área de } \\
\text { estudo? }\end{array}$ & Se sim & Se não \\
\hline$X 16$ & Conhecimento técnico é importante? & Se sim & Se não \\
\hline$X 17$ & $\begin{array}{l}\text { Participar do DS auxiliou na definição de seus } \\
\text { objetivos profissionais? }\end{array}$ & Se sim & Se não \\
\hline$X 18$ & $\begin{array}{l}\text { Um jogo como o DS é importante e contribui na } \\
\text { sua formação futura. }\end{array}$ & Se sim & Se não \\
\hline
\end{tabular}

Tabela 1: variáveis compreendidas no modelo.

O questionário segrega a amostra em dois tipos possíveis de participantes: os participantes que obtiveram sucesso e progrediram para a segunda etapa do Desafio SEBRAE e os que obtiveram insucesso em progredir para a segunda fase do jogo. Definidos sucesso e insucesso, pode-se definir $\operatorname{Prob}[\mathrm{Y}=1]=\mathrm{F}(\mathrm{x}, \beta)$ como a probabilidade de se observar um caso de sucesso e $\operatorname{Prob}[\mathrm{Y}=0]=1-\mathrm{F}(\mathrm{x}, \beta)$ como a probabilidade de se observar um caso de insucesso.

Os modelos probit e logit são uma extensão do modelo de probabilidade linear que incorporam em sua estrutura distribuições de probabilidade (GUJARATI, 2000). Como $F(x, \beta)$ pode ser vista como uma distribuição de probabilidades, fica evidente que seria possível analisar a relação entre as probabilidades de sucesso e insucesso na segunda fase do DESAFIO SEBRAE a partir deste tipo de modelo.

Segundo Wooldridge (2002), a razão entre as probabilidades de sucesso e insucesso é não linear nos parâmetros, ferindo um dos pressupostos clássicos do modelo de regressão linear. Entretanto, pode-se demonstrar que o log desta razão (conhecido por logit e probit, de acordo com a função de distribuição acumulada empregada) é linear nos parâmetros.

Devido a necessidade da utilização de $\log s$ e anti $\log s$ na estimação deste tipo de modelo e, devido a não linearidade nos parâmetros, a estimação não deve ser feita por Mínimos Quadrados Ordinários, mas sim, pelo método de máxima verossimilhança, onde cada observação é tratada como um único resultado de uma distribuição de Beunoulli.

Nestes modelos, é necessário definir também as probabilidades condicionadas da variável 


\section{DETERMINANTES PARA A FORMAÇÃO DA CULTURA EMPREENDEDORA: A EXPERIÊNCIA DO PROJETO DESAFIO SEBRAE.}

dependente, Y, como função das dezoito variáveis explicativas apresentadas no quadro X1; isto é feito da maneira que se segue.

No modelo probit, a probabilidade de se observar um caso de sucesso ( $\mathrm{Y}=1$ ), condicionada a um vetor de variáveis explicativas possui uma distribuição normal padrão; ou seja (WOOLDRIDGE, 2002

$$
\operatorname{Prob}(Y=1 \mid x)=\int_{-\infty}^{x^{\prime} \beta} \phi(t) d t=\Phi\left(x^{\prime} \beta\right)
$$

Já no caso do logit, a distribuição utilizada é a distribuição logística:

$$
\operatorname{Prob}(\mathrm{Y}=1 \mid \mathrm{x})=\frac{\mathrm{e}^{\mathrm{x}^{\prime} \beta}}{1+\mathrm{e}^{\mathrm{x}^{\prime} \beta}}=\Lambda\left(x^{\prime} \beta\right)
$$

A distribuição logística, embora seja um pouco mais densa nas caudas, é bastante similar à distribuição normal, deste modo, para valores intermediários das duas distribuições tendem a fornecer probabilidades similares.

A distribuição logística tende a dar probabilidades maiores para Y=0 quando é extremamente pequeno (e probabilidades menores para $Y=0$ quando é muito grande) em relação à distribuição normal, entretanto, em muitas aplicações, não parece fazer muita diferença a utilização de um modelo ou outro (WOOLDRIDGE, 2002).

\section{Análise e Discussão dos dados}

Neste trabalho foram realizados cálculos considerando ambas as distribuições (tanto a logística quanto a normal). Alinhado à literatura, os resultados do modelo probit são muito semelhantes ao do modelo logit, assim, optou-se por apresentar ambos, porém, discutir apenas os resultados do modelo logit.

O cálculo do efeito marginal foi realizado para o modelo com distribuição logística tanto para o critério da média das variáveis quanto para o critério da chance proporcional, com a magnitude dos efeitos marginais levando-se em conta estes dois critérios. Na Tabela 2 são apresentados os

\begin{tabular}{|c|c|c|c|c|c|c|c|c|c|c|c|c|}
\hline & \multicolumn{6}{|c|}{ LOGIT } & \multicolumn{6}{|c|}{ PROBIT } \\
\hline & \multicolumn{3}{|c|}{ Equação Estimada } & \multicolumn{3}{|c|}{$\begin{array}{l}\text { Probabilidade } \\
\text { Constante }\end{array}$} & \multicolumn{2}{|c|}{$\begin{array}{l}\text { Equação } \\
\text { Estimada }\end{array}$} & & \multicolumn{3}{|c|}{$\begin{array}{l}\text { Probabilidade } \\
\text { Constante }\end{array}$} \\
\hline & $Y=0$ & $Y=1$ & Total & $Y=0$ & $Y=1$ & Total & $Y=0$ & $Y=1$ & Total & $Y=0$ & $Y=1$ & Total \\
\hline$P(Y=1)<=C$ & 37 & 4 & 41 & 40 & 40 & 80 & 36 & 4 & 40 & 40 & 40 & 80 \\
\hline$P(Y=1)>C$ & 3 & 36 & 39 & 0 & 0 & 0 & 4 & 36 & 40 & 0 & 0 & 0 \\
\hline Total & 40 & 40 & 80 & 40 & 40 & 80 & 40 & 40 & 80 & 40 & 40 & 80 \\
\hline Correto & 37 & 36 & 73 & 40 & 0 & 40 & 36 & 36 & 72 & 40 & 0 & 40 \\
\hline
\end{tabular}
resultados que consideram o critério da chance proporcional: 
Maurício Mendes Boavista de Castro, Sérgio Aquino de Souza, João Carlos Hipolito B.

Nascimento, Leonardo Victor de Sá Pinheiro, Juliana Reis Bernardes

Correto

(\%)

$$
92.590
$$

91.25

$100 \quad 0 \quad 50$

9090

90

$100 \quad 0$

50

Incorreto

$\begin{array}{lllllllllllll}\text { (\%) } & 7.5 & 10 & 8.75 & 0 & 100 & 50 & 10 & 10 & 10 & 0 & 100 & 50\end{array}$

Acerto

Total

$-7.590$

41.25

$-10 \quad 90 \quad 40$

Acerto (\%)

NA 90

82.5

NA $\quad 90 \quad 80$

Tabela 2: poder de predição da estimação dos modelos Logit e Probit.

0 algoritmo de maximização utilizado precisou de 8 interações para convergir. 0 valor da função log-verossimilhança no ponto máximo é apresentado na Tabela 3, bem como o valor da estatística de razão de verossimilhança para testar a restrição de que todos os regressores (dezoito) fossem iguais a zero.

\begin{tabular}{|c|c|c|c|c|c|c|c|c|}
\hline & LOGIT & & & & PROBIT & & & \\
\hline Variável & Coeficiente & Erro Pad & Estat. Z & Prob. & Coeficiente & Erro Pad & Estat. Z & Prob. \\
\hline$C$ & -124.949 & 46.828 & -26.683 & 0.0076 & -68.943 & 19.090 & -36.116 & 0.0003 \\
\hline$X 1$ & 45.523 & 11.542 & 39.441 & 0.0001 & 25.970 & 0.6524 & 39.806 & 0.0001 \\
\hline$X 2$ & -27.395 & 20.414 & -13.420 & 0.1796 & -17.081 & 11.250 & -15.183 & 0.1289 \\
\hline$X 3$ & 34.988 & 11.353 & 30.817 & 0.0021 & 20.647 & 0.6329 & 32.621 & 0.0011 \\
\hline$X 4$ & 12.841 & 12.706 & 10.106 & 0.3122 & 0.6735 & 0.6437 & 10.463 & 0.2954 \\
\hline$X 5$ & 66.405 & 16.195 & 41.003 & 0.0000 & 38.776 & 0.9179 & 42.247 & 0.0000 \\
\hline$X 6$ & -37.513 & 16.260 & -23.072 & 0.0210 & -22.247 & 0.9054 & -24.572 & 0.0140 \\
\hline$X 7$ & 36.183 & 13.625 & 26.556 & 0.0079 & 20.870 & 0.6829 & 30.563 & 0.0022 \\
\hline$X 8$ & -0.3124 & 12.066 & -0.2589 & 0.7957 & -0.1954 & 0.6297 & -0.3103 & 0.7563 \\
\hline$X 9$ & -16.496 & 10.184 & -16.198 & 0.1053 & -0.9561 & 0.5719 & -16.718 & 0.0946 \\
\hline$X 10$ & -15.388 & 13.101 & -11.745 & 0.2402 & -0.8401 & 0.7337 & -11.451 & 0.2522 \\
\hline$X 11$ & -0.5737 & 10.586 & -0.5419 & 0.5879 & -0.2673 & 0.5655 & -0.4727 & 0.6365 \\
\hline$X 12$ & 45.299 & 15.503 & 29.220 & 0.0035 & 25.223 & 0.6697 & 37.662 & 0.0002 \\
\hline$X 13$ & 0.0005 & 12.712 & 0.0004 & 0.9997 & -0.0227 & 0.5814 & -0.0391 & 0.9688 \\
\hline$X 14$ & -44.754 & 17.082 & -26.199 & 0.0088 & -25.817 & 0.8721 & -29.602 & 0.0031 \\
\hline$X 15$ & 37.408 & 13.746 & 27.214 & 0.0065 & 21.402 & 0.7993 & 26.774 & 0.0074 \\
\hline$X 16$ & -31.792 & 10.412 & -30.534 & 0.0023 & -18.525 & 0.5581 & -33.194 & 0.0009 \\
\hline$X 17$ & 40.817 & 17.003 & 24.005 & 0.0164 & 22.549 & 0.8627 & 26.137 & 0.0090 \\
\hline
\end{tabular}




\section{DETERMINANTES PARA A FORMAÇÃO DA CULTURA EMPREENDEDORA: A EXPERIÊNCIA DO PROJETO DESAFIO SEBRAE.}

$\begin{array}{lllllllll}\boldsymbol{X 1 8} & 57.465 & 19.482 & 29.497 & 0.0032 & 32.396 & 10.001 & 32.392 & 0.0012\end{array}$

Tabela 3: estimativas dos modelos Logit e Probit.

0 ponto crítico para um qui-quadrado com 18 graus de liberdade dado um nível de significância de $5 \%$, é de 28,87. 0 valor da estatística da razão de máxima verossimilhança (79.3587) aponta para a rejeição da hipótese nula. 0 p-valor representa a probabilidade de ocorrência de um erro do tipo I. 0 p-valor da estatística da razão de verossimilhança é inferior a 0,05, o que indica que a hipótese nula deve ser rejeitada ao nível de significância de 5\%.

Os resultados do modelo apresentam ainda duas medidas de ajustamento. Uma é o $R^{2}$ de McFadden, apresentado na Tabela 4, o qual sugere que os dados possuem um grau de ajuste ao modelo de aproximadamente $72 \%$. A outra medida é o percentual de valores corretamente preditos, o qual fornece o percentual corretamente predito de 1's, quando a probabilidade é maior do que certo valor crítico; e de zeros, quando a probabilidade é menor do que um certo valor crítico (o valor crítico estabelecido no estudo foi de 0,5 ).

\begin{tabular}{lll}
\hline & Logit & Probit \\
\hline Média da Variável Dependente & 0.50 & 0.50 \\
Erro Padrão da Regressão & 0.2889 & 0.2930 \\
Soma dos Quadrados dos Resíduos & 5.0902 & 5.2368 \\
Log da Função de Verossimilhança & -15.7724 & -15.5612 \\
Restr. log likelihood & -55.4518 & -55.4518 \\
Estatística LR (18 g.l) & 79.3587 & 79.7811 \\
Probabilidade (LR stat) & 0.0000 & 0.0000 \\
Desvio Padrão da Variável Dependente & 0.5032 & 0.5032 \\
Critério de Informação de Akaike & 0.8693 & 0.8640 \\
Critério de Informaçao de Schwarz & 1.4350 & 1.4298 \\
Critério de Informaçao de Hannan-Quinn & 1.0961 & 1.0908 \\
Média do Log de Verossimilhança & -0.1972 & -0.1945 \\
$R^{2}$ de McFadden & 0.7156 & 0.7194 \\
Interações Necessárias para Convergência & 8 & 7 \\
\hline
\end{tabular}

Tabela 4: Estatísticas para análise global dos modelos Logit e Probit

A proporção de valores corretamente preditos para $Y=1$ é de $90 \%$ e a proporção de valores corretamente preditos para $\mathrm{Y}=0$ é de $92,5 \%$, como pode ser visto na Tabela 4 . Tais resultados levam a um valor ponderado de predições corretas de 91,25\%. No entanto, é razoável ter-se em mente que medidas de ajustamento em modelos de escolha binária não são importantes nem do ponto de vista estatístico nem do ponto de vista econômico para avaliar a significância das variáveis explicativas (WOOLDRIDGE, 2002). 0 teste da razão de máxima verossimilhança e os 


\section{Maurício Mendes Boavista de Castro, Sérgio Aquino de Souza, João Carlos Hipolito B. Nascimento, Leonardo Victor de Sá Pinheiro, Juliana Reis Bernardes}

testes individuais de significância são suficientes para a avaliação do modelo neste sentido.

A razão entre o coeficiente estimado e o erro padrão (os erros padrão foram estimados utilizando o método de Huber/White no intuito de evitar possíveis problemas de variância heterocedástica dos resíduos) representa uma estatística distribuída assintoticamente como uma distribuição normal padrão (Estatística z). Esses valores são utilizados para a realização do teste de hipótese sobre a significância estatística de cada um dos parâmetros estimados. Como se pode observar nas estatísticas de teste, as variáveis X2, X4, X8, X9, X10, X11 e X13 não se mostraram estatisticamente significativas, ao nível de significância de $5 \%$ (valor crítico de 1,96).

0 p-valor das demais variáveis é inferior a 0,05, o que sugere que a hipótese nula de que o coeficiente seja igual a zero deve ser rejeitada. Assim, com exceção das sete variáveis citadas anteriormente, todas as demais são estatisticamente significantes.

\section{Interpretação do modelo}

A variável sexo possui coeficiente positivo indicando que a variação na razão de probabilidades em favor do sucesso (o logit) varia no mesmo sentido de um incremento desta variável, ou seja, se o indivíduo for do sexo masculino o log da razão de probabilidades em favor do sucesso tende a aumentar. 0 efeito marginal calculado para esta variável é de aproximadamente $0,2 \%$ (Aproximadamente 30\% para o critério da média). Isto sugere que, para cada indivíduo do sexo feminino que seja substituído por um do sexo masculino dentro da amostra, o log da razão de probabilidades em favor do sucesso tende a aumentar em $0,2 \%$; Ou seja, o sexo masculino parece ter contribuído positivamente para a probabilidade de se conseguir passar para a segunda fase do DESAFIO SEBRAE.

A variável idade apresenta um coeficiente estimado negativo de 2.7395 , entretanto, não é estatisticamente significante (estatística Z de -1.3420). Deste modo, não se deve rejeitar a Hipótese nula de que a mesma seja igual a zero e a análise do efeito marginal desta variável não cabe aqui, ou seja, idade parece não ser um fator determinante para a probabilidade de se conseguir passar para a segunda fase do DESAFIO SEBRAE.

A variável X3 (uma variável binária que indica 1, se o indivíduo reside com os pais e 0 , caso contrário) teve um coeficiente estimado de 3,498761; o valor deste coeficiente também resulta num efeito marginal de $0,1 \%$, ou seja, a residência com os pais também parece ter contribuído positivamente para a probabilidade de se conseguir passar para a segunda fase do DESAFIO SEBRAE.

Em relação ao estudo, o ensino fundamental, quando privado, parece influenciar o log da razão de probabilidades em favor do sucesso de maneira extremamente positiva (coeficiente de 6.6405 e efeito marginal de aproximadamente $0,3 \%$ ), pois esta é a variável estatisticamente significante que demonstrou o maior efeito na margem dentro do modelo. No tocante ao ensino médio, entretanto, os resultados não foram os esperados; o coeficiente negativo e estatisticamente significante de 3.7513 acompanhado de um efeito marginal de $-0,2 \%$ revela que o ensino médio privado influencia o log da razão de probabilidades em favor do insucesso. Este resultado pode ser decorrente de algum tipo de problema amostral e sugere que o ensino médio privado parece não colaborar de maneira positiva para que o indivíduo progrida para a segunda fase do DS.

No tocante à profissão dos pais, o fato do pai trabalhar no setor privado contribui para uma variação positiva no logit em favor do sucesso, conforme se vê no coeficiente estimado de X7, na sua estatística $\mathrm{Z}$ e em seu efeito marginal. A profissão da mãe, entretanto, parece não ter 


\section{DETERMINANTES PARA A FORMAÇÃO DA CULTURA EMPREENDEDORA: A EXPERIÊNCIA DO PROJETO DESAFIO SEBRAE.}

influência alguma sobre o logit, pois a mesma é estatisticamente insignificante.

A participação no DS em "edições" anteriores (X12), a crença de que o Desafio SEBRAE auxilia de maneira positiva na definição dos objetivos profissionais (X17) assim como na formação futura do indivíduo (X18) também parecem colaborar de maneira positiva no logit em favor do sucesso, pois todas essas variáveis são estatisticamente significantes ao nível de $5 \%$ e possuem efeitos marginais positivos $(0,2 \%, 0,2 \%$ e $0,3 \%$, respectivamente).

A intenção de ter o próprio negócio possui coeficiente positivo e estatisticamente significante, entretanto, o efeito marginal desta variável $(0,00002)$ é praticamente desprezível. 0 exercício de uma atividade profissional parece contribuir de maneira negativa no logit em favor do sucesso ($0,2 \%)$, entretanto, se esta atividade profissional estiver relacionada à área de estudo, a contribuição torna-se positiva $(0,2 \%)$.

Por fim, a variável $X 16$, que simboliza a crença de que o conhecimento técnico é fator determinante para que os indivíduos sejam bem sucedidos profissionalmente, possui coeficiente negativo e estatisticamente significante com um efeito marginal associado de $0,1 \%$.

Como foi ressaltado anteriormente, as demais variáveis (X2, X4, X8, X9, X10, X11 e X13) não se mostraram estatisticamente significantes e, devido a isto, parecem não ter influência sobre o logit.

\section{Considerações Finais}

O trabalho busca avaliar de que forma algumas variáveis contribuem para a formação da capacidade empreendedora dos estudantes universitários piauienses. As evidências empíricas aqui relatadas são baseadas num modelo logit que busca analisar quais os fatores determinantes capazes de contribuir para o desenvolvimento do empreendedorismo destes jovens.

Admite-se na pesquisa que o empreendedorismo está intimamente ligado à probabilidade de se concluir com êxito a segunda fase do Desafio SEBRAE. Nossos resultados sugerem que indivíduos (i) do sexo masculino, (ii) que residem com os pais, que (iii) possuem um patriarca que exerce atividades no setor privado, que (iv) cursaram o ensino fundamental em colégios privados, que (v) tem intenção de abrir um negócio e que, (vi) quando exercem alguma profissão, atuam na área de seus estudos, contribuem positivamente para a probabilidade de se conseguir passar para a segunda fase do DESAFIO SEBRAE.

Dois resultados não ficaram em conformidade com os resultados esperados. A análise sugere que (i) o ensino médio privado e a crença de que (ii) o conhecimento técnico é fator determinante para que os indivíduos sejam bem sucedidos profissionalmente, parecem não colaborar de maneira positiva para a probabilidade de progressão para a segunda fase do Desafio SEBRAE. Acredita-se que o primeiro resultado pode ser decorrente de algum tipo de problema amostral ocasionado devido à má interpretação do questionário (o entrevistado pode ter confundido ensino médio com ensino superior, por exemplo).

Em relação à sugestão de que o conhecimento técnico influencia positivamente a razão de probabilidades em favor do insucesso, não identifica-se tal sugestão de forma puramente negativa. Na realidade, vê-se que este quesito funciona como um "termômetro" para se averiguar a ênfase que os alunos universitários estão dando ao que eles aprendem na universidade.

0 resultado negativo corrobora com o fato de que ainda está faltando mecanismos no ensino superior para uma disseminação eficaz e eficiente da cultura empreendedora junto ao corpo 
discente. Deste modo, pode-se concluir que o jogo virtual Desafio SEBRAE parece vir cumprindo seu papel, seja completando a lacuna não preenchida pelo sistema de ensino superior padrão, seja motivando a cultura empreendedora dos alunos através da incursão prática que as simulações de mercado oferecem a estes.

Diante de tais conclusões, pode-se observar que a política de aplicação de jogos e/ou simulações nas escolas e instituições formadoras de futuros profissionais de mercado, sejam elas públicas ou privadas, ajudam muito na sua formação empreendedora.

Assim, pode-se fomentar uma geração futura de profissionais empreendedores que contribuirão para a geração de trabalho e renda e, consequentemente, possibilidade para que os gestores públicos possam aplicar maiores esforços em ações de infraestruturas.

Como limitação de pesquisa, o presente estudo foi desenvolvido somente com estudantes piauienses e seus resultados podem não refletir na realidade de outras localidades, deste modo seus achados não podem ser generalizados. Recomenda-se para futuras pesquisas, desenvolver estudos segregados por regiões para efeitos de comparabilidades dos seus resultados.

\section{Referências}

AGHION, P.; HOWITT, P. Appropriate growth policy: a unifying framework. Annual Congress of the European Economic Association, Amsterdam, 20, 2005.

AUDRETSCH, D. B.; KEILBACH, M. C.; LEHMANN, E. E. Entrepreneurship and economic growth. New York: Oxford University Press, 2006.

BARROS, Aluízio Antonio de; PEREIRA, Cláudia Maria Miranda de Araújo. Empreendedorismo e Crescimento Econômico: uma Análise Empírica. Revista de Administração Contemporânea (RAC), Curitiba, v. 12, n. 4, p. 975-993, Out./Dez. 2008.

COTTON, J. Enterprise Education Experience. Durhan, Durhan University Business School. 1990.

DOLABELA, Fernando. Oficina do Empreendedor. São Paulo: Editora Cultura. 1999.

FERREIRA, Armando Leite. Rota de Navegação: Desafio SEBRAE. Rio de Janeiro: Expertbooks. 2007.

FILION, Louis J. Empreendedorismo e gerenciamento: processos distintos, porém complementares. São Paulo: Revista de Administração de Empresas. V. 40. N 3. Jul/Set. 2000.

FREITAS, S.C.; SANTOS, L.P.G. Os benefícios da utilização das simulações empresariais: um estudo exploratório. In: Encontro Anual da Associação dos Programas de Pós-graduação em Administração, 29, 2005, Brasília, Anais... 29ํ ENANPAD. EPQ-B2364, CD-ROM.

GERBER, Juliano Zaffalon. Proposta de Metodologia para o desenvolvimento de recursos à aplicação de jogos de empresas via internet - o modelo para o jogo de empresas GI-EPS. Dissertação de Mestrado - Programa de Pós-Graduação em Engenharia de Produção. UFSC. Florianópolis. 2000.

GOLDSCHMIDT, P.C. Simulação e jogo de empresas. Revista de Administração de Empresas, v.17, n.3, p.43-46, Rio de Janeiro: FGV, maio/jun.1977.

GRAMIGNA, Maria Rita Miranda. Jogos de Empresas. São Paulo: Editora Makron Books. 2000; 


\section{DETERMINANTES PARA A FORMAÇÃO DA CULTURA EMPREENDEDORA: A EXPERIÊNCIA DO PROJETO DESAFIO SEBRAE.}

GUJARATI, Damodar N. Econometria Básica. 3a edição. São Paulo: Makron Books, 2000.

INSTITUTO BRASILEIRO DE GEOGRAFIA E ESTATÍSTICA (IBGE). Censo Demográfico 2010. Disponível em: < http://www.ibge.gov.br/home/estatistica/ populacao/censo2010/>. Acesso em 12 Dez. 2013.

KRUGMAN, P.; WELLS, R. Introdução À Economia. São Paulo: Campus, 2012. 960 p.

LAKATOS, Eva Maria, MARCONI, Marina de Andrade. Fundamentos de metodologia científica. São Paulo: Atlas, 2000.

LOPES, P.C. Formação de Administradores: uma abordagem estrutural e técnico-didática. 2001. Tese (Doutorado em Engenharia de Produção) - Universidade Federal de Santa Catarina. Florianópolis, 2001. 210p.

MARCOVITCH, Jacques. Pioneiros e Empreendedores. V. 2. São Paulo: Edusp. 2005. 328 p.

PINDYCK, R; RUBINFELD, D. L. Econometric models and economic forecasts. 4⿳亠丷a ed. McGrawHill, 1977.

PIRES, CLAYTON DE OLIVEIRA; OI, RICARDO KENJI; TEIXEIRA, ELIANE DE ALCÂNTARA. A Contribuição dos Jogos de Empresas no Desenvolvimento das Características Empreendedoras na Visão dos Alunos de Administração de Empresas. In: Simpósio de Excelência em Gestão e Tecnologia, 9, 2012, Resende - RJ, Anais... 9o SEGeT., CD-ROM.

PORTAL BRASIL. Mapa das micro e pequenas empresas. Disponível em: < http://www.brasil.gov.br/economia-e-emprego/2012/02/o-mapa-das-micro-e-pequenasempresas $>$. Acesso em 12 Dez. 2013.

PRADO, P. H. M.; MARCHETTI, R. Z. A Automação Comercial e a Satisfação do Consumidor em Supermercados. In: ANGELO, C. F. de; SILVEIRA, J. A. G. Varejo Competitivo. São Paulo: Atlas, 1996, p. $15-32$.

PRETTO, F. N. Pedagogia participativa na formação de Administradores. 2007. Tese (Doutorado em Administração de Empresas) - Faculdade de Economia, Administração e Contabilidade, Universidade de São Paulo, 2007, São Paulo.

QMS. Eviews - User's Guide. Irvine, Califórnia: Quantitative Micro Software. 1998.

ROSAS, ANDRÉ ROSENFELD; SAUAIA, ANTONIO CARLOS AIDAR. Jogos de empresas na educação superior no Brasil: perspectivas para 2010. Enfoque: Reflexão Contábil, v. 25, n. 3, p.72-85, 2006.

SANTOS, ROBERTO VATAN DOS. "Jogos De Empresas" Aplicados ao Processo de Ensino e Aprendizagem de Contabilidade. Revista Contabilidade \& Finanças - USP, São Paulo, n. 31, p. 78 - 95, janeiro/abril 2003.

SAUAIA, A. C. A. Jogos de empresas: tecnologia e aplicação. Dissertação de mestrado nãopublicada, Universidade de São Paulo, São Paulo, SP, Brasil, 1989.

(__ J Jogos de empresas: aprendizagem com satisfação. Revista de Administração. São Paulo. v. 32, n. 3, p.13-27, jul-set, 1997.

SAUAIA. A. C. A.; ZERRENNER, S. A. Jogos de empresas e economia experimental: um estudo da 
racionalidade organizacional na tomada de decisão. Revista de Administração Contemporânea (RAC), Curitiba, v. 13, n.2, at.2, p. 189-209, abr./jun. 2009.

SCHUMPETER, J. A. A teoria do desenvolvimento econômico. São Paulo: Editora Nova Cultura. 1997.

(__ ). Teoria do desenvolvimento econômico. (L. Schlaepfer, Trad.). Rio de Janeiro: Fundo de Cultura, 1961.

(__ Capitalismo, socialismo e democracia (S. G. de Paula, Trad.). Rio de Janeiro: Zahar, 1984.

SERVIÇO BRASILEIRO DE APOIO ÀS MICRO E PEQUENAS EMPRESAS (SEBRAE). Sobrevivência das Empresas no Brasil. Disponível em: < http://bis.sebrae.com.br/OpacRepositorioCentral/paginas/downContador.zhtml?uid=93772f4f 62b0716c573d3a9ed5a6a3aa>. Acesso em 12 Dez. 2013.

SENGE, Peter. A quinta disciplina. São Paulo: Editora Best Seller. 1990.

SEXTON, N. P.; KASARDA, J.D. (eds.). The state of art of entrepreneurship. Boston, PWS-Kent Publishing, 1992.

SOUZA, Eda Castro Lucas de. Empreendedorismo: da Gênese à Contemporaneidade. In: 2005.

SOUZA, Eda Castro Lucas de; GUIMARÃES, Tomás de Aquino. Empreendedorismo: além do plano de negócios. São Paulo: Atlas. 2005.

SOUZA, Eda Castro Lucas de. Métodos, Técnicas e Recursos Didáticos de Ensino de Empreendedorismo em IES Brasileiras. In: SOUZA, Eda Castro Lucas de; GUIMARÃES, Tomás de Aquino. Empreendedorismo: além do plano de negócios. São Paulo: Atlas. 2005

STAHL, L.M.; LOPES, P.C. Estratégias de avaliação para jogos de empresas gerais: avaliando desempenho ou aprendizagem. In: Encontro Anual da Associação dos Programas de Pósgraduação em Administração, 28, 2004, Curitiba, Anais... 28ํ ENANPAD. EPA-2160, CD-ROM.

STEVENSON, William J. Estatística Aplicada à Administração. São Paulo: Editora Harbra. 1997.

TANABE, M. Jogos de Empresas. Dissertação (Mestrado) - Faculdade de Economia, Administração e Contabilidade, Universidade de São Paulo. São Paulo, 1973. 120 p.

WARSCHAUER, C.L. Jogos de empresas na área de produção: programação e controle da produção. Revista de Administração de Empresas, v. 17, n.3, p.47-48, Rio de Janeiro: FGV, maio/jun.1977.

WOOLDRIDGE, J. M. Econometric Analysis of Cross Section and Panel Data. The MIT Press. Cambridge. 2002. 
